\title{
How senior paramedics decide to cease resuscitation in pulseless electrical activity out of hospital cardiac arrest: a mixed methods study
}

\author{
Ali Coppola ${ }^{1 *}$ B, Sarah Black ${ }^{2}$ and Ruth Endacott ${ }^{3,4}$
}

\begin{abstract}
Background: Evidenced-based guidelines on when to cease resuscitation for pulseless electrical activity are limited and support for paramedics typically defaults to the senior clinician. Senior clinicians include paramedics employed to work beyond the scope of clinical guidelines as there may be a point at which it is reasonable to cease resuscitation. To support these decisions, one ambulance service has applied a locally derived cessation of resuscitation checklist. This study aimed to describe the patient, clinical and system factors and examine senior clinician experiences when ceasing resuscitation for pulseless electrical activity.
\end{abstract}

Design and methods: An explanatory sequential mixed method study was conducted in one ambulance service in the South West of England. A consecutive sample of checklist data for adult pulseless electrical activity were retrieved from 1st December 2015 to 31st December 2018. Unexpected results which required exploration were identified and developed into semi-structured interview questions. A purposive sample of senior clinicians who ceased resuscitation and applied the checklist were interviewed. Content framework analysis was applied to the qualitative findings.

Results: Senior clinicians ceased resuscitation for 50 patients in the presence of factors known to optimise survival: Witnessed cardiac arrest $(n=37,74 \%)$, bystander resuscitation $(n=30,60 \%)$, defibrillation $(n=22,44 \%)$, return of spontaneous circulation $(n=8,16 \%)$. Significant association was found between witnessed cardiac arrest and bystander resuscitation $(p=.00)$. Six senior clinicians were interviewed, and analysis resulted in four themes: defining resuscitation futility, the impact of ceasing resuscitation, conflicting views and clinical decision tools. In the local context, senior clinicians applied their clinical judgement to balance survivability. Multiple factors were considered as the decision to cease resuscitation was not always clear. Senior clinicians deviated from the checklist when the patient was perceived as non-survivable.

Conclusion: Senior clinicians applied clinical judgement to assess patients as non-survivable or when continued resuscitation was considered harmful with no patient benefit. Senior clinicians perceived pre-existing factors with duration of resuscitation and clinical factors known to optimise patient survival. Future practice could look beyond a set criteria in which to cease resuscitation, however, it would be helpful to investigate the value or threshold of factors associated with patient outcome.

*Correspondence: alison.coppola@swast.nhs.uk

${ }^{1}$ MClinRes Research Paramedic, South Western Ambulance Service NHS

Foundation Trust, Abbey Court, Eagle Way, Exeter, UK

Full list of author information is available at the end of the article

(c) The Author(s) 2021. Open Access This article is licensed under a Creative Commons Attribution 4.0 International License, which permits use, sharing, adaptation, distribution and reproduction in any medium or format, as long as you give appropriate credit to the original author(s) and the source, provide a link to the Creative Commons licence, and indicate if changes were made. The images or other third party material in this article are included in the article's Creative Commons licence, unless indicated otherwise in a credit line to the material. If material is not included in the article's Creative Commons licence and your intended use is not permitted by statutory regulation or exceeds the permitted use, you will need to obtain permission directly from the copyright holder. To view a copy of this licence, visit http://creativecommons.org/licenses/by/4.0/. The Creative Commons Public Domain Dedication waiver (http://creativeco mmons.org/publicdomain/zero/1.0/) applies to the data made available in this article, unless otherwise stated in a credit line to the data. 
Keywords: Paramedic, Pulseless electrical activity, Out of hospital cardiac arrest, Resuscitation

\section{Background}

In the United Kingdom (UK), pulseless electrical activity (PEA) is the first documented rhythm in $32.7 \%$ of adult out of hospital cardiac arrests (OHCA), with 5.3\% of patients surviving to hospital discharge [1]. The incidence of PEA has increased year on year from $21.17 \%$ in 2014 with little improvement to patient outcomes. UK paramedics manage PEA according to advanced life support (ALS) guidelines provided by the Joint Royal College Ambulance Liaison Committee (JRCALC), informed by the UK and European Resuscitation Councils [2]. JRCALC guidelines state there is limited evidence on when to start, continue or cease resuscitation. It is well acknowledged that research focusing on PEA is particularly challenging [3]. Limited diagnostic capabilities and treatment options outside that of standard ALS further limit the evidence base. However, early recognition of cardiac arrest, presence of basic cardiopulmonary resuscitation, defibrillation and post resuscitation care can optimise patient survival [4]. In contrast, long duration of resuscitation, morbidity, absent return of spontaneous circulation (ROSC) and reversible causes are factors found in patients unlikely to survive [2].

Unwitnessed cardiac arrest, no basic life support and a persistent non-shockable cardiac arrest rhythm was previously applied as termination of resuscitation criteria. However, research to validate this criteria found unexpected survivors $(9 \%)$. Therefore, no termination criteria have been adopted into clinical practice [5]. Clinical guidelines in the UK suggest paramedics request senior clinician advice as PEA presents a challenge to decisionmaking and for some patients there may be a point where it is reasonable to cease resuscitation [2].

OHCA were previously found to be resuscitated in non-survivable circumstances [6]. To continue resuscitation in patients with no hope of survival raises an ethical debate regarding patient care and dignity in death [7]. The European Resuscitation Council congress 2021 highlighted the importance of resuscitation decisions from an ethical perspective, considering context of best interest decisions and where the harm versus the benefit of resuscitation are fully appreciated by the clinician. Certainly, approaches to the ethics of resuscitation vary, however, in the UK paramedics work within their scope of clinical practice and boundaries of employment [8], with limited autonomy to implement beneficence and non-maleficence to withhold resuscitation without senior clinician involvement.
In one UK ambulance service, a team of senior clinicians, termed senior clinical advisors (SCAs) are autonomous paramedics who work outside the usual scope of paramedic practice [9]. SCAs provide $24 \mathrm{~h}$ 'on call' remote telephone support to on-scene paramedics who lack the clinical autonomy to cease resuscitation for adult PEA. SCAs apply a locally derived checklist amended from JRCALC guidelines [2] to support and document cessation of resuscitation. To our knowledge how SCAs make the decision to cease resuscitation has not previously been explored. In this study we aim to describe the patient, clinical and system factors of PEA and examine SCA experiences when ceasing resuscitation.

\section{Study objectives}

1. To describe patient, clinical and system factors of out of hospital cardiac arrest patients with PEA when resuscitation was ceased by an SCA.

2. To examine associations between variables known to optimise patient survival.

3. To explore the experiences of SCAs making cessation of resuscitation decisions.

\section{Patient and public involvement and engagement (PPIE)}

PPIE to prioritise research in the public interest and improve the quality of research is an expected commitment when conducting research in the UK [10]. This study was presented to the participating ambulance service PPIE group. The group consisted of eight members including one cardiac arrest survivor and five research paramedics. The consensus was an appropriate research question and methodology. The group highlighted paramedics should cease resuscitation based on individual circumstances, with family wishes and quality of life important factors to consider when collecting data. The group highlighted that not all paramedics would seek SCA advice and the sample size may be small. Interviews were felt appropriate to collect qualitative data given the sensitive nature of resuscitation decisions. However, it was felt a range of interview platforms should be offered, face to face, video, telephone or email due to the geographical location and shift work commitments of participants.

\section{Design and methods Mixed methods design}

In emergency care mixed methodology provides a pragmatic approach to integrate both qualitative and 
quantitative paradigms resulting in a better understanding of the research findings compared to one method alone [11]. The objectives of this study required both quantitative and qualitative methods and a pragmatic epistemology offered the opportunity to gain new knowledge by embracing both [12]. The mixed methods twophase explanatory sequential design was selected most appropriate to answer the research question. Quantitative data was collected and analysed followed by qualitative data to help explain the connected points found in the results (Table 1) [12].

\section{Quantitative data collection}

Cessation of resuscitation checklists for PEA were routinely collected and the primary source of the quantitative data ("Appendix 1"). The checklists recorded patient demographics, clinical findings and a free text box to document the rationale for ceasing the resuscitation. A retrospective consecutive sample was collected from December 2015 to December 2018. Additional data items were sourced from patient clinical records, computer aided dispatch system and the cardiac arrest registry comprising of patient, system and clinical factors (Table 2).

Patient identifiable information was redacted, and retrospective consent was not required as data was anonymised.

\section{Exclusion criteria}

Cases subject to coronial or police investigation and paediatric patients below 18 years were excluded.

\section{Quantitative data analysis}

Descriptive statistics were applied to all variables. Continuous variables were reported as mean and standard deviation (Sd) for parametric data or median and interquartile range (IQR) for non-parametric data. Categorical variables were summarised as counts and percentages. Free text box information (family wishes, rationale for cessation of resuscitation) was manually grouped into categories of similar meaning and counted. Chi Square and independent $\mathrm{t}$-tests were performed on factors known to optimise survival. $P$ values less than 0.05 were considered statistically significant. No power calculation was required for this study. Statistical analysis was conducted using SPSS version 24 [13].

Quantitative data were interpreted for significant and non-significant results, outliers and group differences. Unexpected results were identified when data was not consistent with typical findings of PEA undergoing resuscitation. These results required further explanation and were interpreted to construct the interview questions for the qualitative study [12].

\section{Qualitative data collection}

A purposive sample of SCAs were selected to provide expert participants who cease resuscitation and complete the checklists. A sample of four to six participants was felt suitable to provide an in-depth examination of the quantitative results [12]. Participants were identified by the ambulance service research team, emailed for expressions of interest and provided with a participant information sheet and research study consent document. A range of interview platforms were offered to reduce barriers of

Table 1 Explanatory sequential design

\begin{tabular}{ll}
\hline Quantitative study & Describe the adult patient, clinical and system factors of pulseless electrical activity \\
Quantitative results & Identify the quantitative results which require further explanation using a qualitative methodology \\
Qualitative study & Apply the quantitative results to inform the semi-structured interview questions \\
Summarise and interpret results & What are connective points between the qualitative findings help to explain the quantitative results?
\end{tabular}

Table 2 Variables for analysis

\begin{tabular}{lll}
\hline Patient factors & System factors & Clinical factors \\
\hline Age & Time of collapse & Adrenaline dose (mg) \\
Gender & Time to basic resuscitation & Progression to a shockable rhythm \\
Arrest witnessed & Time to advanced resuscitation & Defibrillation \\
Bystander resuscitation & Duration of arrest & End-tidal carbon dioxide \\
Co-morbidities & Duration of basic life support (BLS) & Heart rate \\
Place of arrest & Duration of advanced life support (ALS) & Return of spontaneous circulation \\
Family wishes considered & Total duration of out of hospital cardiac arrest & Rationale for cessation of resuscitation \\
\hline
\end{tabular}


participation. Virtual interviews whilst considered a poor substitute compared to face-to-face interviews offer participants the opportunity to answer questions in their own time, reflect and edit responses, comfort when disclosing sensitive information and validation of responses by following up answers [14].

Semi-structured interview questions were used to collect data whilst enabling participants the freedom to elaborate and explore emerging topics. Eight interview questions were developed and piloted by a critical care paramedic (Table 7). Interviews were conducted by the lead author. Interviews applied reflective validation as an alternative to member checking to reduce bias and increase the trustworthiness and credibility of answers [15]. Confidentiality and anonymity were maintained by allocating non-identifiable codes to each interview. Email correspondence used encryption over a secure NHS network.

\section{Qualitative data analysis}

Interview transcripts were analysed using content framework analysis. Analysis consisted of five stages (1) familiarisation (2) identifying thematic framework (3) indexing of codes (4) charting of themes (5) mapping and interpretation of findings [16]. As interview questions were constructed using the quantitative results, there were some 'a priori' themes to guide the initial deductive analysis. Additional themes emerged through inductive analysis. Data coding was managed using NVIVO 11.4.2 [17]. Reflexivity was supported using a diary to bracket assumptions and minimise influence during data collection and analysis. Data was cross coded and verified by two independent researchers of different professional backgrounds. The consolidated criteria for reporting qualitative research checklist (COREQ) was applied [12].

\section{Setting}

Emergency medical systems in the UK consist of ambulance services, staffed by paramedics trained in ALS. Paramedics are defined as "a registered health professional who work across a range of health and care settings, as well as in education, leadership and research" [9]. This research study was conducted in a single ambulance service operating 100 sites across an area of $10,000 \mathrm{mi}^{2}$ with a population of 5.5 million. The ambulance service attends up to 3000 incidents per day and approximately 4000 resuscitations each year [18].

\section{Ethics}

Institutional ethics approval was provided by the ambulance service (ref 17-018) and the University (reference 1718424).

\section{Results}

Cardiac arrest registry data was available for 32 months from 1st April 2016 to 31st December 2018. The total number of cardiac arrests were 10,246 and 1823 reported PEA as the initial rhythm. The average annual cardiac arrest rate was 3842. The annual PEA rate was 683: the incidence of PEA was $18 \%$ of these $54 \%(n=368)$ of patients were transported to hospital; $46 \%(n=315)$ of patients died at scene and $6 \%(\mathrm{n}=43)$ of patients survived to hospital discharge. During the study period SCAs were contacted regarding 57 patients. SCAs requested paramedics continue resuscitation for seven patients (12\%) and resuscitation was ceased in 50 patients $(88 \%)$. The patient, system and clinical factors of the 50 patients where resuscitation was ceased were analysed in detail. As a yearly average $6 \%(n=19)$ of PEA patients who died at the scene of the cardiac arrest had SCA involvement.

\section{Patient factors}

In one ambulance service SCAs ceased resuscitation for 50 patients with PEA. The median age was 78.50 years (IQR: 69, 84). The majority of patients were male $(\mathrm{n}=30$, $60 \%)$, located at a residential address $(\mathrm{n}=44,88 \%)$, had a witnessed cardiac arrest $(\mathrm{n}=37,74 \%)$ and received basic resuscitation $(n=30,60 \%)$. Co-morbidities were documented for the majority of patients $(\mathrm{n}=40,80 \%)$ of which $51 \%$ were cardiac with a previous history of myocardial infarction, aortic aneurysm, cardiac failure, hypertension and $8 \%$ respiratory with chronic obstructive pulmonary disease. Family wishes were documented in the free text box, cross referenced with the patient clinical record and considered in $32 \%(n=16)$ of patients.

\section{System factors}

System factors are reported in Table 3. The duration of BLS and lone ambulance BLS were similar (0:07:30, 0:07:35). Duration of ALS was below $55 \mathrm{~min}$, however, the total duration of OHCA was nearly $1 \mathrm{~h}$ and $10 \mathrm{~min}$ when no flow and BLS times were included.

\section{Clinical factors}

Clinical factors are reported in Table 4. PEA was the only reported rhythm for 18 patients (36\%). A rhythm change was reported in 32 patients (64\%), 12 patients (26\%) intermittently transitioned to asystole and 20 patients $(38 \%)$ converted to a shockable rhythm. ROSC was achieved intermittently and was not sustained for longer than $10 \mathrm{~min} . \mathrm{ETCO}_{2}$ value was recorded prior to confirmation of death. A median dose of $6 \mathrm{mg}$ of adrenaline was administered. Guidelines state $1 \mathrm{mg}$ every 3-5 min, however, this study reports a mean ALS duration of $54 \mathrm{~min}$. This duration should have resulted in a 
Table 3 System factors

\begin{tabular}{lll}
\hline System factors & N (\%) & Duration hr:min:sec \\
\hline No flow time ${ }^{\&}$ median (IQR) & $50(100)$ & $0: 07: 30(4.46-15.25)$ \\
Duration of BLS median (IQR) & $26(52)$ & $0: 07: 35(4.58-16.01)$ \\
Duration of lone ambulance BLS ${ }^{\ddagger}$ median (IQR) & $23(46)$ & $0: 07: 32(5.31-15.9)$ \\
Duration of ALS mean (SD) & $50(100)$ & $0: 54: 46(0: 16: 59)$ \\
Duration of resuscitation ${ }^{\wedge}$ (BLS \& ALS) mean (SD) & $50(100)$ & $0: 59: 32(0: 17: 39)$ \\
Total duration of out of hospital cardiac arrest mean (SD) & $50(100)$ & $1: 09: 23(0: 19: 53)$ \\
\hline
\end{tabular}

\& No flow time, time from collapse to the start of resuscitation

${ }^{€}$ Lone ambulance responders (community responders, advanced technicians, paramedics, duty officers) providing BLS only

\# ALS time of ambulance arrival to confirmation of death

${ }^{\wedge}$ Duration of out of hospital cardiac arrest, no flow time to confirmation of death

Table 4 Clinical factors

\begin{tabular}{|c|c|c|}
\hline Clinical factors & $\mathrm{N}(\%)$ & \\
\hline Defibrillation & $22(44)$ & \\
\hline Return of spontaneous circulation (ROSC) & $8(16)$ & \\
\hline End-tidal carbon dioxide $\left(\mathrm{ETCO}_{2}\right)$ (kilopascal, kPa) (Mean) & $44(88)^{\mathrm{a}}$ & $2.3(2.0-4.4)$ \\
\hline Adrenaline Dose (1 mg/10 ml) median (IQR) & $50(100)$ & $6.0(5.0-7.5)$ \\
\hline PEA rate $<50$ beats per minute (BPM) & $46(92)$ & \\
\hline
\end{tabular}

${ }^{\text {a }}$ Missing $\mathrm{ETCO}_{2}$ data for 6 patients

Table 5 Association between factors known to optimise patient survival

\begin{tabular}{lll}
\hline Factors & Result \\
\hline Witnessed cardiac arrest & Bystander BLS & $p 0.000$ \\
Witnessed cardiac arrest & Defibrillation & $p 0.856$ \\
Bystander BLS & Defibrillation & $p 0.103$ \\
Witnessed cardiac arrest & ROSC & $p 0.418$ \\
Bystander BLS & ROSC & $p 0.875$ \\
\hline
\end{tabular}

cumulative adrenaline dose of $11 \mathrm{mg}$. This may reflect the time to venous access or interruptions caused by rhythm changes, defibrillation or ROSC.

The association between factors known to optimise patient survival are reported in Tables 5 and 6 . The only significant association was found between witnessed cardiac arrest and bystander resuscitation $\left(x^{2} n=50, d f 1=p\right.$ 0.000).

\section{SCA rationale for ceasing resuscitation}

In the checklist free text box, SCAs documented 161 reasons for ceasing resuscitation. Reasons were grouped into similar meaning, counted and categorised. Clinical factors were most considered, low $\mathrm{ETCO}_{2}$ values, no ROSC and persistent PEA $(\mathrm{n}=117$, $71.7 \%)$. Patient factors included family wishes and progressive illness $(n=30,19.6 \%)$. System factors included the duration of resuscitation and extended transfer times to hospital $(n=14,8.5 \%)$.

The results identified a number of PEA patients presenting with factors known to optimise survival; witnessed cardiac arrest, bystander resuscitation, defibrillation, $\mathrm{ETCO}_{2}$ value and ROSC, albeit intermittent. These results were used to construct the semi-structured interview questions to examine in detail why the resuscitation was ceased (Table 7 ).

Table 6 Duration of ALS for patients with ROSC/no ROSC and defibrillation/no defibrillation

\begin{tabular}{lllllll}
\hline & $\begin{array}{l}\text { No defib } \\
M(S D)\end{array}$ & $\begin{array}{l}\text { Defib } \\
M(S D)\end{array}$ & $p$-value & $\begin{array}{l}\text { No ROSC } \\
M(S D)\end{array}$ & $\begin{array}{l}\text { ROSC } \\
M(S D)\end{array}$ & $p$-value \\
\hline Duration of ALS & $53: 25(0: 16.45)$ & $56.29(0: 17.31)$ & 0.531 & $53: 32(0: 17.34)$ & $1: 01: 16(0: 12.25)$ & 0.242 \\
\hline${ }^{\$}$ T-test & & &
\end{tabular}




\section{Interview findings}

Six SCAs participated. Five telephone and one email interview were conducted. SCAs were mixed gender, the average age was 40 years (35-47 years), clinical experienced averaged 14 years and 'on call' rota experience ranged between 6 months and 9 years. Telephone interviews lasted between $28-54 \mathrm{~min}$. The email interview dialogue was developed over several days to provide an in-depth narrative of answers.

Data analysis generated 349 codes, 12 sub-themes and four main themes. One 'a priori' theme was derived from the quantitative data: defining a futile resuscitation. Three further themes emerged during data analysis, the impact of ceasing resuscitation, perceived conflict between the SCA and on-scene paramedics and supportive tools for ceasing resuscitation. Illustrative data excerpts are presented in Table 8.

\section{Defining a futile resuscitation}

SCAs applied multiple factors to identify when ceasing resuscitation was appropriate. No one factor was considered, however, age, co-morbidity, persistent PEA, morphology, low $\mathrm{ETCO}_{2}$, no or intermittent ROSC and prolonged resuscitation were highlighted along with a perceived poor quality of life or a natural end of life event.

I think about that question in context things like age, rhythm, end tidal capnography, heart rate, morphology previous medical conditions and events preceding the event are probably some of the key factors I'd be thinking about. (SP1)

SCAs described interpreting these factors to provide a good history of the event and a holistic view of the patient. SCAs then applied their knowledge, experience and acumen to determine if the patient had reached a natural end of life or was beyond surviving.

An older person I'm more likely to allow them to cease a PEA but that would be based on what their quality of life is like, if they are in a nursing home bedbound or they play golf and run marathons its taking their quality of life as one of the considerations. (SP2)

\section{The impact of ceasing resuscitation}

Repeated exposure to ceasing resuscitation increased confidence and the decision-making process became more comfortable over time; however, SCAs highlighted that the decision to cease resuscitation was not always easy or clear.

I got to a position of confidence, sometimes I had to work at, it I never felt it was a wrong decision to make or that I was second guessing myself once I've hung up but on occasion it took me a while to get there. (SP4)

SCAs carefully considered and reflected upon their decisions. Despite being relatively confident ceasing the resuscitation was correct, the decision could carry an emotional burden. Resuscitation decisions when woken at night were found particularly challenging with human factors adding to the complexity of decision-making.

They are difficult decisions to make and are often disruptive, especially at night when you are woken up, often I find it difficult to fall back to sleep as I reflect on my decision and feel a sense of loss for the family. (SCA6)

\section{Perceived conflict between the SCA and on-scene paramedic}

A number of SCAs highlighted conflict between themselves and the on-scene paramedic. SCAs felt pressured to cease resuscitation and found paramedics were not always prepared to discuss the survivable aspects.

I think paramedics maybe on the whole need a bit more education around PEA and when patients are survivable. (SP1)

Table 7 Results for further examination

\begin{tabular}{ll}
\hline Quantitative result & Question \\
\hline Witnessed cardiac arrest 74\% & 1. How do witnessed cardiac arrest influence a cessation decision? \\
Bystander BLS 60\% & 2. How does bystander resuscitation influence a cessation decision? \\
Defibrillation $44 \%$ & 3. How do rhythm changes influence a cessation decision? \\
Mean end-tidal carbon dioxide value $2.3 \mathrm{kPa}$ & 4. What are your views on end-tidal values when ceasing resuscitation? \\
Mean duration of resuscitation $54 \mathrm{~min}$ & 5. Is there a duration of resuscitation beyond which you would cease resuscitation? \\
Multiple factors reported when ceasing resuscitation & 6. Which factors influence your resuscitation decisions the most? \\
Variation in rationales to cease resuscitation & 7. Why was there variation in the rationales to cease resuscitation? \\
SCA involvement in $6 \%$ of patients who died at the scene & 8. What are your thoughts on SCA support and remote decisions? \\
\hline
\end{tabular}


Table 8 Illustrative data excerpts

\begin{tabular}{|c|c|}
\hline Theme & Defining a futile resuscitation \\
\hline Key features & $\begin{array}{l}\text { "things like age, rhythm, end tidal capnography, previous medical conditions and events preceding the } \\
\text { event are probably some of the key factors l'd be thinking about." (SP1) }\end{array}$ \\
\hline A poor quality of life & $\begin{array}{l}\text { "quality of life I know there's lots of controversy about should you use that as an indicator, but I find it } \\
\text { useful to know in terms of if in the nicest possible way if the patients in a nursing home bedbound with } \\
\text { severe dementia and comorbidities there's something about should we be resuscing anyway." (SP5) }\end{array}$ \\
\hline A perceived natural end of life & $\begin{array}{l}\text { "I may feel more confident to say actually if it was an older person or more of the elder category then to } \\
\text { consider that that might be their natural end of life." (SP3) }\end{array}$ \\
\hline Theme & The impact of ceasing resuscitation \\
\hline Confidence gained with experience and exposure & $\begin{array}{l}\text { "I am confident in making a decision yes I've been making it for enough years so I feel confident in mak- } \\
\text { ing it... is it always clear cut? No." (SP5) }\end{array}$ \\
\hline Critical awareness and self-reflection & "I feel confident with my decisions but I do rethink every decision that I made remotely" (SP3) \\
\hline The weight of responsibility when deciding futility & $\begin{array}{l}\text { "It did have its moments going about your daily business and you think bloody hell that is a bit hardcore } \\
\text { so it's very easy writing out a word document on your form and filling it in but when you actually put } \\
\text { someone's name in it and all their bits and pieces its quite oh actually someone just died and sometimes } \\
\text { that was more stressful more poignant that being there." (SP4) }\end{array}$ \\
\hline Theme & Perceived conflict between senior and on-scene paramedics \\
\hline $\begin{array}{l}\text { Senior paramedic/SCA? clinical knowledge, expe- } \\
\text { rience and accountability }\end{array}$ & $\begin{array}{l}\text { I don't think crews have a great understanding of PEA they don't necessarily know or fully understand the } \\
\text { potential for reversible causes". (SP2) }\end{array}$ \\
\hline Clinical leadership and moral judgements & $\begin{array}{l}\text { "I would say that from my experience of it that you can make a decision with a degree of separation from } \\
\text { what's going on so you can take a reasoned history and then consider the factors without the back- } \\
\text { ground noise if you like and the human factors that come into play from a stressful on scene environ- } \\
\text { ment". (SP4) }\end{array}$ \\
\hline Conflict between senior and on-scene paramedic & $\begin{array}{l}\text { "They are trying to sell me a situation to fulfil their own agenda so their selling me a patient that's pro- } \\
\text { foundly unwell when there actually a survivable aspect to it because it is frustrating". (SP4) }\end{array}$ \\
\hline Theme & Supportive tools for cessation of resuscitation decisions \\
\hline The 'checklist' as a safety net & "I think the fallback option which is used is just follow a checklist in order for safe practice." (SP1) \\
\hline Checklist deviation and sound clinical reasoning & $\begin{array}{l}\text { "Cessation of resuscitation checklist which we should use which helps govern our decision making....... } \\
\text { if a patient doesn't fall within that then we have to be pretty confident and be very careful about calling a } \\
\text { cessation of resuscitation attempt." (SP1) }\end{array}$ \\
\hline Checklist and moving forward & $\begin{array}{l}\text { "I do think the checklist that we are using is almost double negative in terms of the questioning and it's } \\
\text { still a little ambiguous in some areas." (SP3) }\end{array}$ \\
\hline
\end{tabular}

SCAs felt remote telephone clinical support provided a degree of separation, enabling the time required to consider all factors to make an informed decision. SCAs acknowledged the limitations of remote support and the disadvantages of not visually interpreting the scene of the OHCA. However, SCAs felt their clinical knowledge and experience informed the decision-making process to ensure decisions were made in the best interest of the patient. At times SCAs felt paramedics lacked the clinical knowledge and were not comfortable with the responsibility and accountability required to cease resuscitation.

Sometimes they are wanting someone else to make that decision, they can say the SCA allowed them to cease resuscitation so I think some paramedics are like that, that someone else has made the decision and I am off the hook, yet we are all registered pro- fessionals all accountable. (SP2)

\section{Supportive tools for ceasing resuscitation}

SCAs referred to the PEA cessation of resuscitation checklist and felt it worked well as a supportive decision tool. The checklist was positively viewed with some uncertainty on how to better standardise the complexities of resuscitation decisions.

Deviation from the checklist was possible with careful considered clinical judgement.

we've got the checklist we can still step outside the check list... but I think if you've got all the SCAs in a room and ran some scenarios I'm not entirely convinced they'd make the same consistent decision. (SP5) 
This occurred when resuscitation was ceased in patients with factors known to optimise survival; witnessed collapse, bystander resuscitation, ROSC or defibrillation. This deviation may have involved one or all of the factors, introducing variation in the care delivered to patients with one SCA stating inconsistent decisionmaking in how the checklist was applied.

I do think the checklist is almost double negative in terms of the questioning and it's still is a little ambiguous, though a more structured form would lead to making the decision to not cease or convey more PEAs, but I do think it probably is a bit dependent on the individual that takes the call to the level of the decision. (SP3)

\section{Synthesis of findings}

The connective points between the quantitative results and qualitative findings were summarised into three categories (1) PEA within a local context (2) SCA experiences of ceasing resuscitation (3) multifactorial decision-making. This process is presented in "Appendix 2".

\section{PEA within a local context}

The results found $46 \%$ of PEA patients died at the scene of the cardiac arrest, however, only $6 \%$ of these had SCA involvement. One explanation may be the conflict perceived by the SCA and the on-scene paramedic. The SCAs felt the on-scene paramedic did not want to discuss the survivable aspects of the cardiac arrest and were telephoning to cease the resuscitation as this was outside their scope of practice.

\section{Senior clinical advisor experiences of ceasing resuscitation} SCAs documented 161 reasons for ceasing the resuscitation in the free text box of the checklist. Factors known to optimise patient survival were present, however, SCAs felt continued resuscitation was not in the best interest of the patient. SCAs felt these patients were not survivable due to a perceived poor quality of life, informed by frailty or morbidity. They felt ceasing resuscitation was not always easy or clear and relied on balancing multiple factors to make a best interest decision.

\section{Multifactorial decision-making}

SCA decision-making was mostly informed by clinical factors. SCAs had different perceptions on the value or threshold of factors which made continued resuscitation inappropriate. One SCA said resuscitation was futile after $20 \mathrm{~min}$, another $45 \mathrm{~min}$ and another $1 \mathrm{~h}$. That's said, decision making was not based on one factor alone and not all factors such as quality of life were easily measurable with different perceptions. SCA decision-making applied clinical judgement informed by their knowledge, experience and acumen.

\section{Discussion}

This study examined how SCAs ceased resuscitation in patients with PEA. Factors known to optimise survival were present within the sample of patients, witnessed cardiac arrest, bystander BLS, defibrillation and ROSC, as evidenced in the chain of survival [19]. Witnessed cardiac arrest and bystander BLS were statistically significant, a similar result to that found in other studies [20]. In this study, defibrillation was administered following conversion from PEA to a shockable rhythm $(n=22,44 \%)$. In a previous study conversion was associated with ROSC but not survival to hospital discharge [21]. SCAs viewed conversion and defibrillation as a positive progression, however, patients who remained in PEA prior to ROSC were previously found to have a more favourable neurological outcome compared to those who converted [22]. ROSC was also viewed positively by the SCAs, however, in this study ROSC was achieved intermittently and not sustained $(\mathrm{n}=8,16 \%)$.

Electrocardiogram (ECG) morphology was well considered with the majority of patients reporting a heart rate below $50 \mathrm{bpm}(\mathrm{n}=46,92 \%)$. A slow heart rate is widely accepted as a poor prognostic marker for survival [23], however, one study found morphology inaccurate to predict patient outcome [24]. A slow wide morphology indicates no cardiac movement, often categorised as a true PEA. A fast narrow morphology, described as pseudo PEA may present with profound hypotension and some cardiac movement [25]. However, there are no clear predefined categories of PEA with one study applying six different morphologies, albeit none associated with survival [26]. The SCAs considered a fast narrow morphology more survivable and this view was supported by one study which found pseudo PEA often mistaken for ROSC. ECG, $\mathrm{ETCO}_{2}$ and ultrasound collectively can help identify ROSC, however, ultrasound is not routinely used by paramedics [27]. ETCO $\mathrm{ET}_{2}$ is routinely monitored and in this study the mean was $2.3 \mathrm{kPa}$. A systematic review investigated $\mathrm{ETCO}_{2}$ to prognosticate resuscitation futility and whilst 
associations were found, no specific value to cease resuscitation could be determined [28]. SCAs reported no optimal value or threshold to cease resuscitation and this was reflected in the literature, suggesting a further investigation to associate $\mathrm{ETCO}_{2}$ and morphology with outcome is required. SCAs considered duration of resuscitation the most important system factor. Once again, previous research was unable to identify an optimal duration with studies reporting anywhere between 10 to $47 \mathrm{~min}[19,29]$. In this study, the mean ALS resuscitation ( $54 \mathrm{~min}$ ) was considered non-survivable by the majority of SCAs.

Patient factors advanced age, frailty and morbidity were interpreted to help the SCAs understand the patients quality of life to inform the possibility of a natural end of life event. SCAs recognised variation in the perceptions surrounding quality of life and previously no accepted method of assessment were identified as an accurate measure [30]. Nor was age found to be an accurate measure of patient outcome [31, 22, 23]. Previous data on prehospital clinical frailty and morbidity and the impact on survival was limited, however, these factors were found to inform resuscitation decisions [29]. In these circumstances, cardiac arrest was not reversible, SCAs were confident to cease resuscitation and were well supported by the guidelines to do so [32]. SCAs acknowledged their perceptions introduced variation in the care delivered to patients, even when applying the checklist to support decision-making.

In this study, SCAs viewed the checklist as a supportive tool, to help reduce human factors. This view was supported by previous studies which found decision tools for cardiac arrest likely to identify patient survival and reduce variation in practice $[33,34]$. That said, another study found checklists to support clinical decisions insufficient as they omitted the multiple factors required to build a holistic view of the patient [35]. This view reflected SCA practice as deviation from the checklist occured when clinical judgement balanced the factors as non-survivable, however, making the decision to cease resuscitation presented a number of challenges.

The SCAs experienced conflict with the paramedics on-scene, which they felt was due to a lack of training or knowledge and an unwillingness to discuss the survivable aspects. This finding was similar to that of a previous study which found conflict between clinicians due to expectation, pressure, personal beliefs and moral practice [36]. Previously paramedics reported feeling underconfident when making resuscitation decisions [37]. SCA forms part of the clinical guideline which underpins UK paramedic practice [2]. In this study SCAs felt shared decision making was beneficial, providing time for reflection to reduce human factors, although the effectiveness of remote support in emergency care has not previously been assessed [38, 39]. Also, from a legal perspective, uncertainty was found regarding which clinician was liable for the decisions, the on-scene clinician or remote support [40]. Interestingly in this study, paramedics made the majority of resuscitation decisions as SCA involvement was limited. Given the paucity of evidence-based guidelines, this finding requires further exploration.

\section{Limitations}

The main limitation of this study was the small sample size. No power calculation was applied as there were no predefined criteria for ceasing resuscitation for PEA. This may have introduced a type II error. Consecutive sampling was applied to capture all SCA checklist data between December 2015-2018. This data was screen by two reviewers against the inclusion criteria, however, the sample reflects the limited involvement of SCAs. Missing data was identified for $\mathrm{ETCO}_{2}$. Severity of morbidity was not reported, nor were clinical frailty scores. The effectiveness of bystander resuscitation or by whom it was conducted was not measured. Researcher bias was acknowledged when conducting the interviews. To reduce bias questions were piloted and data was cross coded by two independent reviewers of different professional backgrounds. One interview was conducted by email, limiting the opportunity to probe the participant responses.

\section{Conclusion}

SCAs applied clinical judgement to assess patients as non-survivable or when continued resuscitation was considered harmful with no patient benefit. SCAs perceived pre-existing factors of morbidity, frailty, age and quality of life with duration of resuscitation and the clinical factors known to optimise patient survival. This multifactorial approach questions the appropriateness of ceasing resuscitation based on clinical factors alone. Future practice could look beyond a set criteria in which to cease resuscitation, however, it would be helpful to investigate the value or threshold of factors associated with patient outcome. 


\section{Appendices}

Appendix 1: SCA Cessation of resuscitation checklist

\begin{tabular}{|c|c|c|}
\hline Clinical Findings & Yes & No \\
\hline VF/VT present & $\square$ & $\square$ \\
\hline Shocks delivered & $\square$ & $\square$ \\
\hline EMS Witnessed & $\square$ & $\square$ \\
\hline Effective bystander CPR prior to arrival. & $\square$ & $\square$ \\
\hline $\begin{array}{l}\text { Sustained ROSC* (consider time, duration, rule out adrenaline induced) } \\
\text { *Sustained for sufficient time to complete the post ROSC care bundle, approximately } 5 \\
\text { minutes. }\end{array}$ & $\square$ & $\square$ \\
\hline $\begin{array}{l}\text { Where present, QRS complexes should be considered for rate and form, or paced } \\
\text { rhythm with no mechanical capture. Record Rate. }\end{array}$ & \multicolumn{2}{|c|}{$\begin{array}{l}\text { Click here to } \\
\text { enter text. }\end{array}$} \\
\hline $\begin{array}{l}\mathrm{EtCO}_{2} \text { Capnography remains above } 1.5 \mathrm{kpa} \text { either immediately after chest compressions } \\
\text { stop or persistently during resuscitation (check tube). Explore sudden sustained } \\
\text { reductions in value. }\end{array}$ & $\square$ & $\square$ \\
\hline Two central pulses present & $\square$ & $\square$ \\
\hline Heart sounds present & $\square$ & $\square$ \\
\hline
\end{tabular}

Brief overview and other considerations (Review best interest decision, social factors, family context, extrication challenges, duration of resuscitation attempt)

Only after consultation with the Senior Clinical Advisor or Consultant Top Cover, can a decision to cease be made in this section.

Specifically consider the patient's wishes expressed previously, verbally or via the family. Consider any suspicious circumstances. Include number of shocks, ROSC details etc.

Click here to enter text. 


\section{Documentation}

\begin{tabular}{|l|l|}
\hline \multicolumn{2}{|l|}{ Decision } \\
\hline Time resuscitation ceased: & Click here to enter text. \\
\hline Rationale \\
Click here to enter text. \\
\end{tabular}

\section{Appendix 2: Framework of results}

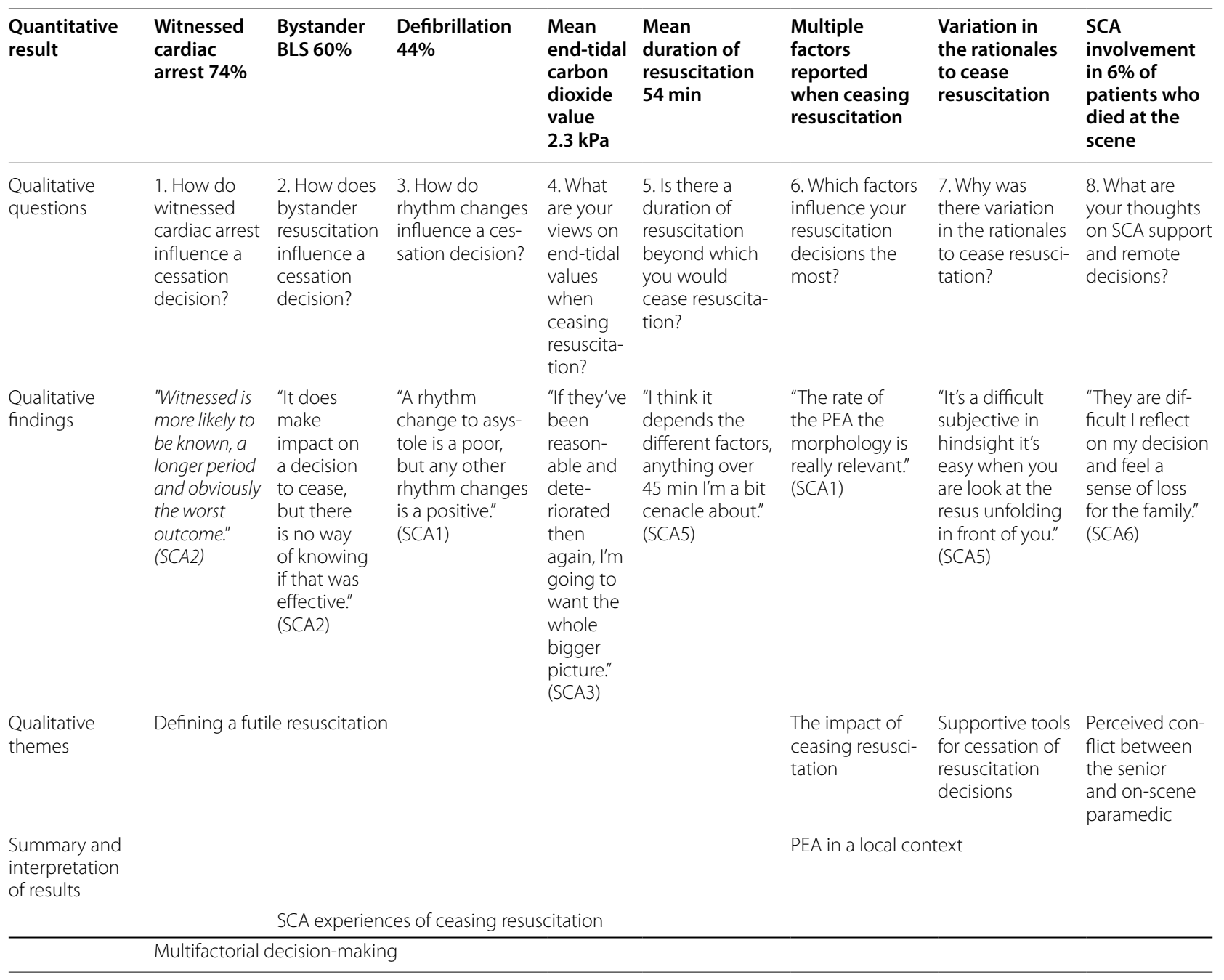




\section{Abbreviations}

ALS: Advanced life support; BLS: Basic life support; ECG: Electrocardiogram; $\mathrm{ETCO}_{2}$ : End tidal carbon dioxide; PEA: Pulseless electrical activity; ROSC: Return of spontaneous circulation; SCA: Senior clinical advisor.

\section{Acknowledgements}

The authors would like to thank Professor Jonathan Benger for his valuable input and guidance as the educational supervisor for this study. Thank you to the SCAs who participated and the collaborators.

\section{Authors' contributions}

AC is the lead author and principal investor for this study. SB made significant contributions to the study design, data collection strategy and editing of this manuscript. RE supervised the collaboration of this manuscript, making significant contributions to the statistical analysis, results, findings and overall editing. All authors read and approved the final manuscript.

\section{Authors' information}

$A C$ is a research paramedic working in the South West of England. AC undertook this original research as part of a master's in clinical research, within the NIHR clinical academic pathway. AC continues to work clinically as a paramedic and recently won NIHR funding for a pre-clinical academic fellowship to write a clinical doctorate fellowship application to continue research focused on reducing variation in the management of OHCA with pulseless electrical activity.

\section{Collaborators}

J. Lynde and H. Trebilcock extracted the quantitative data. M Hawley piloted interview questions. L. Tremayne and E. Freeman edited and second coded the qualitative data.

\section{Disclaimer}

The views expressed in this publication are those of the author(s) and not necessarily those of the National Health Service, the NIHR, the Department of Health and Social Care or the authors' employers.

\section{Funding}

Ali Coppola, Pre-Clinical Academic Fellow, NIHR301003 is funded by Health Education England (HEE)/National Institute for Health Research (NIHR) for this project. The views expressed in this publication are those of the author(s) and not necessarily those of the NIHR, NHS or the UK Department of Health and Social Care, South western ambulance service NHS foundation trust or the University of Plymouth.

\section{Availability of data and materials}

An anonymised patient data set and anonymised participant transcripts are available from the author on request.

\section{Declarations}

\section{Ethics approval and consent to participate}

Institutional ethics approval was provided by the South western Ambulance Service NHS foundation Trust (ref 17-018) and the University of Plymouth (reference 1718424). Retrospective consent was not required as patient data was fully anonymised. Participant written consent for SCAs was gained.

\section{Consent for publication}

All data is fully anonymised. Written consent of was gained for each participant, including for publication.

\section{Competing interests}

The authors declare no competing interests.

\section{Author details}

${ }^{1}$ MClinRes Research Paramedic, South Western Ambulance Service NHS Foundation Trust, Abbey Court, Eagle Way, Exeter, UK. ${ }^{2}$ Head of Research, Audit and Quality Improvement, South Western Ambulance Service NHS Foundation Trust, Exeter, UK. ${ }^{3}$ School of Nursing and Midwifery (Faculty of Health: Medicine, Dentistry and Human Sciences), University of Plymouth,
Plymouth, UK. ${ }^{4}$ School of Nursing and Midwifery, (Faculty of Medicine, Nursing and Health Sciences), Monash University, Melbourne, Australia.

Received: 29 March 2021 Accepted: 26 August 2021

Published online: 16 September 2021

\section{References}

1. OHCAO Project Team. Out-of-Hospital Cardiac Arrest Outcomes Registry Epidemiology Report, 2018 English Ambulance Services. 2019.

2. Joint Royal Colleges Ambulance Liaison Committee/Association of ambulance chief executives. JRCALC Clinical Practice Guidelines. 2015. https://aace.org.uk/clinical-practice-guidelines/. Accessed 1 Jan 2015.

3. Myerburg RJ, Halperin H, Egan DA, Boineau R, Chugh SS, Gillis AM, et al. Pulseless electric activity: definition, causes, mechanisms, management, and research priorities for the next decade: report from a national heart, lung, and blood institute workshop. Circulation. 2013;128(23):2532-41.

4. Soar J, Deakin C, Lockey A, Nolan J, Perkins G. Adult advanced life support. 2015. https://www.resus.org.uk/resuscitation-guidelines/adultadvanced-life-support/\#reversible. Accessed 18 May 2018.

5. Skrifvars M, Vayrynen T, Kuisma M, Castren M, Parr M, Silfverstople J, et al. Comparison of Helsinki and European Resuscitation Council "do not attempt to resuscitate" guidelines, and a termination of resuscitation clinical prediction rule for out-of-hospital cardiac arrest patients found in asystole or pulseless electrical activity. 2010. http://search.ebscohost. com/login.aspx?direct =true\&AuthType $=i p, u r l$, shib\&db=rzh\&AN $=10520$ 4064\&site=ehost-live. Accessed 11 Oct 2017.

6. Cokljat M, Clegg G, Clarke S. An audit into the number of patients suffering out-of-hospital cardiac arrest that are resuscitated despite a high likelihood of futility. Emerg Med J. 2017. http://www.ncbi.nlm.nih.gov/ pubmed/29170321. Accessed 18 May 2018.

7. Brandling J, Kirby K, Black S, Voss S, Benger J. Emergency medical service provider decision-making in out of hospital cardiac arrest: an exploratory study. BMC Emerg Med. 2017. https://doi.org/10.1186/ s12873-017-0136-3.

8. Bossaert LL, Perkins GD, Askitopoulou H, Raffay VI, Greif R, Haywood KL, et al. European Resuscitation Council Guidelines for Resuscitation 2015 Section 11. The ethics of resuscitation and end-of-life decisions on behalf of the ethics of resuscitation and end-of-life decisions section Collaborators 1. Resuscitation. 2015. https://doi.org/10.1016/j.resuscitation.2015.07. 033.

9. College of Paramedics. Paramedic Post-Graduate Curriculum Guidance. 2017. https://www.collegeofparamedics.co.uk/downloads/para_post_ grad_curric_guide_2017_(FINAL).pdf. Accessed 18 Jan 2020.

10. Roberts L, Turner K, Williamson T. INVOLV briefing notes for researchers: public involvement in NHS public health and social care research. 2012.

11. Cooper S, Porter J, Endacott R. Mixed methods research: a design for emergency care research? Emerg Med J. 2011;28(8):682-5.

12. Creswell JW, Plano Clark VL. Designing and conducting mixed methods research. Thousand Oaks: SAGE Publications; 2011. p. 457.

13. IMP Corp. IBM How to cite IBM SPSS Statistics or earlier versions of SPSS. 2016. http://www-01.ibm.com/support/docview.wss?uid=swg21476197. Accessed 25 June 2019.

14. Clarke $\vee$, Braun V. Successful qualitative research: a practical guide for beginners. Thousand Oaks: Sage Publication; 2014.

15. Harvey L. Beyond member-checking: a dialogic approach to the research interview. Int J Res Method Education. 2015. https://doi.org/10.1080/ $1743727 X .2014 .914487$.

16. Srivastava A, Thomson SB. Framework analysis: a qualitative methodology for [Internet]. Vol. 4, Applied Policy Research. JOAAG. 2009. http://resea rch.apc.org/images/a/ad/Framework_analysis.pdf. Accessed 28 July 2018.

17. Bazeley P, Jackson K. Qualitative data analysis with NVivo. Thousand Oaks: SAGE Publications; 2013. p. 307.

18. South Western Ambulance Service NHS Foundation Trust. Annual Report and Accounts 1 April 2018-31 March 2019. 2014.

19. Ong M, Perkins G, Cariou A. Out-of-hospital cardiac arrest: prehospital management. Lancet. 2018. www.thelancet.com. Accessed 29 May 2020.

20. Brown T, Booth S, Hawkes C, Fothergill R, Black S, Pocock H, et al. Who receives bystander CPR in a witnessed out-of-hospital cardiac arrest in 
England. Resuscitation. 2018. https://doi.org/10.1016/j.resuscitation.2018. 07.204 .

21. Juarez JM, Koller A, Salcido D, Menegazzi J. Electrocardiographic rhythm transitions associated with outcomes in non-shockable out-of-hospital cardiac arrest. Resuscitation. 2018;130:e35.

22. Zheng R, Luo S, Liao J, Liu Z, Xu J, Zhan H, et al. Conversion to shockable rhythms is associated with better outcomes in out-of-hospital cardiac arrest patients with initial asystole but not in those with pulseless electrical activity. Resuscitation. 2016;107:88-93.

23. Skjeflo G, Nordseth T, Loennechen J, Bergum D, Skogvoll E. ECG changes during resuscitation of patients with initial pulseless electrical activity are associated with return of spontaneous circulation. Resuscitation. 2018;127:31-6.

24. Ho ML, Gatien M, Vaillancourt C, Whitham V, Stiell IG. Utility of prehospital electrocardiogram characteristics as prognostic markers in out-of-hospital pulseless electrical activity arrests. Emerg Med J. 2018;35(2):89-95.

25. Littmann L, Bustin D, Haley M. A simplified and structured teaching tool for the evaluation and management of pulseless electrical activity. Med Princ Pract. 2014;23(1):1-6.

26. Bergum D, Skjeflo G, Nordseth T, Mjølstad O, Haugen B, Skogvoll E, et al. ECG patterns in early pulseless electrical activity-associations with aetiology and survival of in-hospital cardiac arrest. Resuscitation. 2016;104:34-9.

27. Paxton $\mathrm{JH}, \mathrm{O}^{\prime}$ Neil BJ. When is PEA really ROSC? Resuscitation. 2019;142:182-3.

28. Touma O, Davies M. The prognostic value of end tidal carbon dioxide during cardiac arrest: a systematic review. Resuscitation. 2013;81:1470-9.

29. Ibitoye S, Rawlinson S, Cavanagh A, Phillips V, Shipway D. Frailty status predicts futility of cardiopulmonary resuscitation in older adults. Age Ageing. 2021;50(1):147-52.

30. Haywood KL, Pearson N, Morrison LJ, Castrén M, Lilja G, Perkins GD. Assessing health-related quality of life (HRQoL) in survivors of out-ofhospital cardiac arrest: a systematic review of patient-reported outcome measures. Resuscitation. 2018. http://www.ncbi.nlm.nih.gov/pubmed/ 29191703. Accessed 6 May 2019.

31. van de Glind E, van Munster B, van de Wetering F, van Delden J, Scholten $\mathrm{RJ}$, Hooft L. Pre-arrest predictors of survival after resuscitation from outof-hospital cardiac arrest in the elderly a systematic review. BMC. 2013. https://doi.org/10.1186/1471-2318-13-68.
32. The British Medical Association the RC (UK) and the RC of N. Decisions Relating to Cardiopulmonary Resuscitation: a joint statement from the British Medical Association, the Resuscitation Council (UK) and the Royal College of Nursing. J Med Ethics. 2016;27:310-6.

33. van Walraven C, Forster A, Parish D, Dane F, Chandra K, Durham M, et al. Validation of a clinical decision aid to discontinue in-hospital cardiac arrest resuscitations. JAMA. 2001;285(12):1602.

34. Cook D, Pencille L, Dupras D, Linderbaum J, Pankratz V, Wilkinson J. Practice variation and practice guidelines: attitudes of generalist and specialist physicians, nurse practitioners, and physician assistants. PLoS ONE. 2018;13(1):e0191943.

35. Van de Velde S, Kunnamo I, Roshanov P, Kortteisto T, Aertgeerts B, Vandvik PO, Flottorp S. The GUIDES checklist: development of a tool to improve the successful use of guideline-based computerised clinical decision support. Implement Sci. 2018. https://doi.org/10.1186/s13012-018-0772-3.

36. Erbay H. Some ethical issues in prehospital emergency medicine. Turk J Emerg Med. 2014;14(4):193-8.

37. Anderson N, Gott M, Slark J. Commence, continue, withhold or terminate: a systematic review of decision-making in out-of-hospital cardiac arrest. 2016.

38. Amadi-Obi A, Gilligan P, Owens N, O'Donnell C. Telemedicine in prehospital care: a review of telemedicine applications in the pre-hospital environment. Int J Emerg Med. 2014;7:29.

39. Nqala $M$, Rout $C$, Aldous C. Remote clinical support by telephone for rural district hospital medical officers in the Eastern Cape. S Afr Fam Pract. 2015;57(5):286-90.

40. NICE. Chapter 4 Paramedic remote support Emergency and acute medical care in over 16s: service delivery and organisation NICE guideline Emergency and acute medical care. 2017.

\section{Publisher's Note}

Springer Nature remains neutral with regard to jurisdictional claims in published maps and institutional affiliations.

Ready to submit your research? Choose BMC and benefit from:

- fast, convenient online submission

- thorough peer review by experienced researchers in your field

- rapid publication on acceptance

- support for research data, including large and complex data types

- gold Open Access which fosters wider collaboration and increased citations

- maximum visibility for your research: over $100 \mathrm{M}$ website views per year

At BMC, research is always in progress.

Learn more biomedcentral.com/submissions 